\title{
In silico design of hydrazone antioxidants and analysis of their free radical-scavenging mechanism by thermodynamic studies
}

\author{
Ikechukwu Ogadimma Alisi ${ }^{1^{*}}$ D, Adamu Uzairu² and Stephen Eyije Abechi ${ }^{2}$
}

\begin{abstract}
Background: Antioxidants are very crucial in maintaining the normal function of body cells, as they scavenge excess free radical in the body. A set of hydrazone antioxidants was designed by in silico screening. The density functional theory (DFT) method was employed to explore the reaction energetics of their free radicalscavenging mechanism. With the aid of the developed quantitative structure-activity relationship (QSAR) model for hydrazone antioxidants, the structure and antioxidant activity of these compounds were predicted. Three potential reaction mechanisms were investigated, namely, hydrogen atom transfer (HAT), single-electron transfer followed by proton transfer (SET-PT) and sequential proton loss electron transfer (SPLET). Bond dissociation enthalpy (BDE), adiabatic ionization potential (AIP), proton dissociation enthalpy (PDE), proton affinity (PA), electron transfer enthalpy (ETE) and Gibbs free energy that characterize the various steps in these mechanisms were calculated in the gas phase.

Results: A total of 25 hydrazone antioxidants were designed, in which the molecule MHD 017 gave the best antioxidant activity. Among the tested molecules, MHD 017 at the $10-\mathrm{OH}$ site gave the best results for the various thermodynamic parameters calculated. The reaction Gibbs free energy results also indicate that this is the most favoured site for free radical scavenge.

Conclusion: The obtained results show that HAT and SPLET mechanisms are the thermodynamically plausible reaction pathways of free radical scavenge by hydrazone antioxidants. The reactivity of these compounds towards the hydroperoxyl radical ( $\mathrm{HOO} \cdot)$ was greater than that towards the methyl peroxyl radical $\left(\mathrm{CH}_{3} \mathrm{OO}\right.$.) based on the exergonicity of the calculated reaction Gibbs free energy.
\end{abstract}

Keywords: Hydrazone, Free radical, Antioxidant, Scavenging mechanism, In silico design

\section{Background}

The hydrazones are a group of compounds that contain the azomethine linkage. This linkage influences the majority of their reactions and properties [13]. The derivatives of hydrazone have been demonstrated to display diverse biological activities which include $\alpha$-glucosidase inhibition [33, 41], antibacterial and anti-fungi $[4,14,16,32,34]$, anticancer $[18,38]$, antitumor [32], anticonvulsant [11], anticholinesterase [20] and antioxidant $[3,7,12,15,19,23]$ activities. Recently, hydrazone derivatives have been employed

\footnotetext{
*Correspondence: ikeogadialisi@gmail.com; ialisi@fudutsinma.edu.ng ${ }^{1}$ Department of Applied Chemistry, Federal University Dutsinma, PMB 5001, Dutsinma, Katsina State, Nigeria

Full list of author information is available at the end of the article
}

as corrosion inhibitors for mild steel and iron [10, 21]. They have also been shown to possess photoprotective capacities [7].

The various metabolic processes that take place in the human system result in the production of free radicals which includes reactive oxygen species (ROS). Excessive and uncontrolled production of reactive oxygen species in the human system is the major cause of various disease conditions such as atherosclerosis, cancer, cardiovascular disorders and oxidative damage to proteins and DNA $[3,19]$. This condition could be prevented by the application of antioxidant therapeutic agents such as hydrazone derivatives with potent antioxidant activities. Antioxidants are able to interact with free radicals and 
terminate the chain reactions that cause their damaging effects in the body.

Virtual screening employs computer-based methods in the design and identification of new chemical entities on the basis of their biological activities. Upon the application of virtual screening, a large collection of compounds can be analysed, and candidates with the best potency subjected to synthesis. The key advantages associated with virtual screening are its ability to control cost, time and wastage encountered when screening a large collection of compounds for a particular biological activity. Two broad categories of virtual screening have been distinguished, namely, docking and ligand-based virtual screening [43]. Docking is a structure-based screening method, while ligand-based virtual screening involves the use of active compounds as templates. The particular chosen screening method depends on the information available for the system. Ligand-based approaches employ pharmacophore or quantitative structure-activity relationship quantitative structure-activity relationship (QSAR) models to screen a broad range of ligands $[24,35]$.

The use of mathematical models such as those generated from QSAR studies, for screening new chemical compounds through the technique of ligand-based virtual screening is gaining popularity in the development of novel compounds with improved biological activities $[5,6,26]$. This research entails a systematic investigation of the free radical-scavenging mechanisms of newly designed hydrazone derivatives by thermodynamic studies. The earlier developed QSAR model for hydrazones [1] was employed in the design of a new set of hydrazone derivatives by ligand-based virtual screening. The antioxidant activities and applicability domain of these compounds were investigated with the aid of the model. The three basic mechanisms of free radical scavenge, namely, hydrogen atom transfer (HAT), singleelectron transfer followed by proton transfer (SET-PT) and sequential proton loss electron transfer (SPLET), were investigated for the designed compounds with best antioxidant potentials via thermodynamic studies. This was accomplished by calculating the various antioxidant parameters such as bond dissociation enthalpy (BDE), adiabatic ionization potential (AIP), proton dissociation enthalpy (PDE), proton affinity (PA) and electron transfer enthalpy (ETE). Subsequently, the highest occupied molecular orbital (HOMO) and the lowest unoccupied molecular orbital (LUMO) distributions of the compounds as well as their radical spin density were evaluated. The DFT method has been found to give an accurate evaluation of the above mentioned reaction enthalpies that characterize the various reaction mechanisms. Subsequently, geometry optimization of all molecular structures was conducted in the gas phase at the density functional theory (DFT) level with B3LYP functional and 6-311G* basis set. Also, the thermodynamically preferred mechanism of the reactions between the considered antioxidants and the two important peroxyl radicals (hydroperoxyl radical (HOO.) and methyl peroxyl radical $\left(\mathrm{CH}_{3} \mathrm{OO}\right)$ ) were evaluated through the computation of their reaction Gibbs free energy.

\section{Methods}

\subsection{Ligand-based virtual screening of new compounds}

The results of the developed QSAR model for hydrazone antioxidants [1] were employed in the design of a new set of hydrazone compounds by ligand-based virtual screening. The applicability domain for the developed model has a leverage threshold $h^{*}$, value of 0.375 .

This was performed by insertion, deletion and substitution of different substitutes on the template molecule as dictated by the developed hydrazone antioxidant model $[6,25,28]$. In the present research, compound M010 (Fig. 1) listed in Table 1 of [1], was chosen as a template based on its good antioxidant activity $\left(p I C_{50}=6.123\right)$. The chemical structures of the compounds were drawn using the Chem Draw Program [22]. With the aid of the Spartan 14 program [39], the resulting structures were minimized and further optimized at the density functional theory (DFT) level using the Becke's three-parameter LeeYang-Parr hybrid functional (B3LYP) and 6-311G* basis set without symmetry constraints. This resulted in the generation of quantum chemical descriptors. The optimized structures were converted to Sdf files and submitted for the generation of molecular descriptors using the PADEL program package version 2.20 [46]. The effects of the structural modifications on the antioxidant activity of the resulting compounds were investigated. Subsequently, the applicability domain of the newly designed compounds was assessed by the leverage approach.

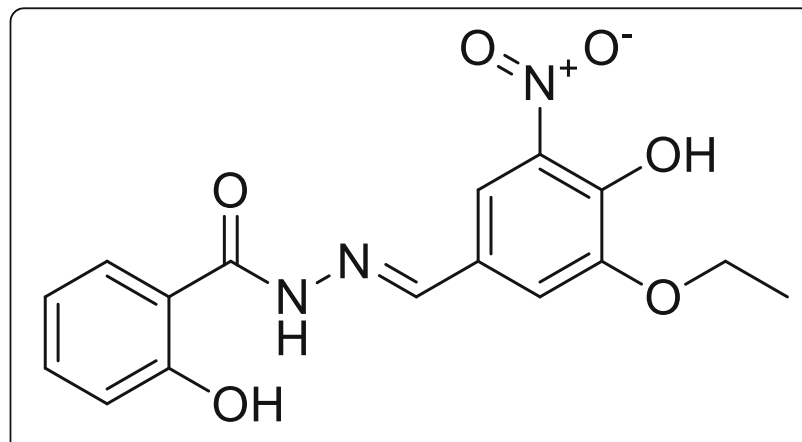

Fig. 1 The parent hydrazone molecule used as a template (M010) 
Table 1 Designed hydrazone antioxidants, their predicted antioxidant activities and leverage values

\begin{tabular}{|c|c|c|c|}
\hline Comp no. & Compound structure/name & $p / C_{50}$ & Leverag \\
\hline MHD 01 & (E)-N'-(3-ethoxy-2,4-dihydroxy-5-nitrobenzylidene)-2,5-dihydroxybenzohydrazide & 6.470 & 0.062 \\
\hline MHD 02 & (E)-5-amino-N'-(2-amino-3-ethoxy-4-hydroxy-5-nitrobenzylidene)-2-hydroxybenzohydrazide & 6.589 & 0.076 \\
\hline MHD 03 & (E)-5-(dichloromethyl)-N'-(2-(dichloromethyl)-3-ethoxy-4-hydroxy-5-nitrobenzylidene)-2-hydroxybenzohydrazide & 5.979 & 0.196 \\
\hline MHD 04 & (E)-5-(difluoromethyl)-N'-(2-(difluoromethyl)-3-ethoxy-4-hydroxy-5-nitrobenzylidene)-2-hydroxybenzohydrazide & 5.925 & 0.194 \\
\hline MHD 05 & (E)-5-(2,2-dichloroethyl)-N'-(2-(2,2-dichloroethyl)-3-ethoxy-4-hydroxy-5-nitrobenzylidene)-2-hydroxybenzohydrazide & 6.424 & 0.330 \\
\hline MHD 06 & (E)-5-(2,2-difluoroethyl)-N'-(2-(2,2-difluoroethyl)-3-ethoxy-4-hydroxy-5-nitrobenzylidene)-2-hydroxybenzohydrazide & 6.432 & 0.398 \\
\hline MHD 07 & (E)-N'-(3-ethoxy-4-hydroxy-5-nitrobenzylidene)-2,4,5-trihydroxybenzohydrazide & 6.478 & 0.062 \\
\hline MHD 08 & (E)-4,5-diaminoN'-(3-ethoxy-4-hydroxy-5-nitrobenzylidene)-2-hydroxybenzohydrazide & 6.575 & 0.073 \\
\hline MHD 09 & (E)-4,5-bis (dichloromethyl)-N'-(3-ethoxy-4-hydroxy-5-nitrobenzylidene)-2-hydroxybenzohydrazide & 5.951 & 0.179 \\
\hline MHD 10 & (E)-4,5-bis (difluoromethyl)-N'-(3-ethoxy-4-hydroxy-5-nitrobenzylidene)-2-hydroxybenzohydrazide & 5.972 & 0.157 \\
\hline MHD 11 & (E)-4,5-bis(2,2-dichloroethyl)-N'-(3-ethoxy-4-hydroxy-5-nitrobenzylidene)-2-hydroxybenzohydrazide & 6.405 & 0.323 \\
\hline MHD 12 & (E)-3-amino-5-(dichloromethyl)-4-(difluoromethyl)-N'-(3-ethoxy-2,4-dihydroxy-5-nitrobenzylidene)-2,6-dihydroxybenzohydrazide & 6.543 & 0.098 \\
\hline MHD 13 & (E)-N'-(3-ethoxy-2,4-dihydroxy-5-nitrobenzylidene)-2,3,4,5,6-pentahydroxybenzohydrazide & 6.607 & 0.253 \\
\hline HD 14 & (E)-2,3,4,5-tetraamino-N'-(2-amino-3-ethoxy-4-hydroxy-5-nitrobenzylidene)-6-hydroxybenzohydrazide & 6.573 & 0.216 \\
\hline MHD 15 & (E)-2,3,4,5-tetrakis (difluoromethyl)-N'-(2-(difluoromethyl)-3-ethoxy-4-hydroxy-5-nitrobenzylidene)-6-hydroxybenzohydrazide & 4.890 & 0.664 \\
\hline MHD 16 & (E)-4-(2,2-dichloroethyl)-N'-(-3-ethoxy-4-hydroxy-5-nitrobenzylidene)-2,6-dihydroxybenzohydrazide & 6.613 & 0.105 \\
\hline MHD 17 & (E)-3,5-diamino-N'-(2-amino-3-ethoxy-4-hydroxy-5-nitrobenzylidene)-2,4,6-trihydroxybenzohydrazide & 6.851 & 0.200 \\
\hline MHD 18 & (E)-2-amino-N'-(2-amino-3-ethoxy-4-hydroxy-5-nitrobenzylidene)-3-(dichloromethyl)-5-(difluoromethyl)-4,6-dihydroxybenzohydrazide & 6.620 & 0.102 \\
\hline MHD 19 & (E)-N'-(3-ethoxy-2,4-dihydroxy-5-nitrobenzylidene)-2,4,6-trihydroxybenzohydrazide & 6.541 & 0.089 \\
\hline MHD 20 & (E)-N'-(3-ethoxy-4-hydroxy-2-mercapto-5-nitrobenzylidene)-2-hydroxy-4,6-dimercaptobenzohydrazide & 6.318 & 0.209 \\
\hline MHD 21 & (E)-2,4-diamino-N'-(2-amino-3-ethoxy-4-hydroxy-5-nitrobenzylidene)-6-hydroxybenzohydrazide & 6.610 & 0.076 \\
\hline MHD 22 & (E)-N'-(2-amino-3-ethoxy-4-hydroxy-5-nitrobenzylidene)-2,4-dihydroxy-6-mercaptobenzohydrazide & 6.783 & 0.115 \\
\hline MHD 23 & (E)-N'-(3-ethoxy-4-hydroxy-5-nitrobenzylidene)-3,4'-dihydroxy-[1,1'-biphenyl]-4-carbohydrazide & 5.439 & 0.069 \\
\hline MHD 24 & (E)-N'-((6-ethoxy-4',5-dihydroxy-4-nitro-[1,1'-biphenyl]-2-yl)methylene)-3,4'-dihydroxy-[1,1'-biphenyl]-4-carbohydrazide & 4.896 & 0.377 \\
\hline MHD 25 & (E)-N'-(3-ethoxy-4-hydroxy-5-nitrobenzylidene)-4,4",5'-trihydroxy-[1,1'3',1"'-terphenyl]-4'-carbohydrazide & 4.904 & 0.378 \\
\hline
\end{tabular}

\subsection{Calculation of antioxidant parameters}

In order to evaluate the preferred mechanism of free radical scavenge, various antioxidant descriptors were calculated as presented below:

The homolytic bond dissociation enthalpy (BDE): This is the standard enthalpy change at a given temperature when a particular chemical bond is broken under standard conditions [37]. The stability of the corresponding hydroxyl group is determined by the value of the BDE. When the BDE value is low, the stability of the corresponding $\mathrm{O}-\mathrm{H}$ bond is low and thus can easily be broken (Fuyu and Ruifa 2013). This gives rise to high antioxidant capacity for the considered compound. This parameter was calculated under standard conditions of $1 \mathrm{~atm}$ and $298.15 \mathrm{~K}$ as presented in Eq. 1.

$$
\mathrm{BDE}=H_{\text {radical }}+H_{\mathrm{H}}-H_{\text {neutral }}
$$

The adiabatic ionization potential (AIP): This potential describes the process of electron donation by the antioxidant. It represents the capacity of the antioxidant to transfer electrons to the free radical. The lower the AIP value for a given molecule, the easier is the capacity to transfer electrons and the higher the susceptibility of that molecule to undergo ionization. Molecules with high to low AIP values have been observed to possess very strong antioxidant properties.

This parameter was estimated according to Eq. 2;

$$
A I P=H_{\text {cation radical }}+H_{\text {electron }}-H_{\text {neutral }}
$$

The proton dissociation enthalpy (PDE): This was also calculated using Eq. 3. PDE is a useful physical parameter that describes the ability of the compounds to donate a proton. Antioxidants with lower values of PDE have been observed to be more susceptible to proton abstraction [27].

$$
\mathrm{PDE}=H_{\text {radical }}+H_{\mathrm{H}^{+}}-H_{\text {cation radical }}
$$

The proton affinity (PA): This may be defined as the negative of the molar enthalpy change at $298.15 \mathrm{~K}$. The lower the PA value, the higher the antioxidant activity. 
This parameter was computed using Eq. (4)

$$
\mathrm{PA}=H_{\text {anion }}+H_{\mathrm{H}^{+}}-H_{\text {neutral }}
$$

The electron transfer enthalpy (ETE): Eq. 5 was employed in the calculation of ETE. The lower the ETE value, the more active is the resulting phenoxide anion for a given molecule.

$$
\mathrm{ETE}=H_{\text {radical }}+H_{\text {electron }}-H_{\text {anion }}
$$

where

$H_{\text {radical }}=$ Total enthalpy of phenoxyl radical.

$H_{\mathrm{H}}=$ Total enthalpy of the hydrogen atom.

$H_{\text {neutral }}=$ Total enthalpy of neutral compound.

$H_{\mathrm{H}^{+}}=$Total enthalpy of the proton.

$H_{\text {cation radical }}=$ Total enthalpy of the cation radical.

$H_{\text {electron}}=$ Total enthalpy of the electron.

$H_{\text {anion }}=$ Total enthalpy of the anion.

In this research, the total enthalpies of the species were calculated as the sum of total electronic energy, zero-point energy and the translational, rotational and vibrational contributions to the total enthalpy (Eq. 6). The RT (PV-work) term was added to convert the energy to enthalpy [29].

$$
H=E_{0}+\mathrm{ZPE}+H_{\text {trans }}+H_{\text {rot }}+H_{\text {vib }}+\mathrm{RT}
$$

where, $H_{\text {trans }}, H_{\text {rot }}$ and $H_{\text {vib }}$ are the translational, rotational, and vibrational contributions to the enthalpy, respectively. $E_{0}$ is the total energy at $0 \mathrm{~K}$, while ZPE is the zero-point vibrational energy.

Also, for the calculation of the antioxidant parameters, the following values were employed: $H\left(H^{*}\right)_{\text {vacuum }}=-$ $1312.479673 \mathrm{~kJ} / \mathrm{mol}, \quad H\left(H^{+}\right)_{\text {vacuum }}=6.1961805 \mathrm{~kJ} / \mathrm{mol}$, and $H\left(e^{-}\right)_{\text {vacuum }}=3.14534924 \mathrm{~kJ} / \mathrm{mol},[8,9,30,36]$.

\subsection{Investigation of the thermodynamically favoured mechanism}

The thermodynamically favoured mechanism is estimated by the reaction Gibbs free energy $\left(\Delta_{r} G\right)$ [2, 47]. In this light, computation of the Gibbs free energy of the reactants and products for the studied mechanisms of the reactions between the antioxidants and the two important peroxyl radicals ( $\mathrm{HOO}$. and $\mathrm{CH}_{3}-\mathrm{OO}$.) were performed.

The reaction between a free radical and an antioxidant is said to be thermodynamically favourable if the reaction Gibbs free energy is negative (Eq. 7).

$$
\Delta_{r} G=[G(\text { products })-G(\text { reactants })]<0
$$

The reaction Gibbs free energy for the HAT mechanism is given by $\Delta_{r} G_{\mathrm{BDE}}$. This was calculated as presented in Eq. 8.

$$
\Delta_{r} G_{\mathrm{BDE}}=\left[G\left(H_{n-1} \text { Antiox }^{*}\right)+G(R H)\right]-\left[G\left(H_{n} \text { Antiox }\right)+G\left(R^{*}\right)\right]
$$

The reaction Gibbs free energy for the SET-PT mechanism is given by $\Delta_{r} G_{\mathrm{AIP}}$ (Eq. 9) and $\Delta_{r} G_{\mathrm{PDE}}$ (Eq. 10).

$\Delta_{r} G_{\text {AIP }}=\left[G\left(H_{n-1}\right.\right.$ Antiox $\left.\left.^{\bullet+}\right)+G\left(R^{-}\right)\right]-\left[G\left(H_{n}\right.\right.$ Antiox $\left.)+G\left(R^{\bullet}\right)\right]$

$\Delta_{r} G_{\mathrm{PDE}}=\left[G\left(H_{n-1}\right.\right.$ Antiox $\left.\left.^{*}\right)+G(R H)\right]-\left[G\left(H_{n-1}\right.\right.$ Antiox $\left.\left.^{\bullet+}\right)+G\left(R^{-}\right)\right]$

Also, the reaction Gibbs free energy for the SPLET mechanism is given by $\Delta_{r} G_{\mathrm{PA}}$ (Eq. 11) and $\Delta_{r} G_{\mathrm{ETE}}$ (Eq. 12).

$$
\Delta_{r} G_{\mathrm{PA}}=\left[G\left(H_{n-1} \text { Antiox }^{-}\right)+G(R H)\right]-\left[G\left(H_{n} \text { Antiox }\right)+G\left(R^{-}\right)\right]
$$

$\Delta_{r} G_{\mathrm{ETE}}=\left[G\left(H_{n-1}\right.\right.$ Antiox $\left.\left.^{*}\right)+G\left(R^{-}\right)\right]-\left[G\left(H_{n-1}\right.\right.$ Antiox $\left.\left.^{-}\right)+G\left(R^{*}\right)\right]$

where

$G\left(H_{n}\right.$ Antiox $)=$ Gibbs free energy of neutral antioxidant.

$G\left(H_{n-1}\right.$ Antiox $\left.^{*}\right)=$ Gibbs free energy of phenoxyl radical.

$G\left(R^{*}\right)=$ Gibbs free energy of free radical.

$G(R H)=$ Gibbs free energy of product formed by hydrogen abstraction to free radical.

$G\left(H_{n-1}\right.$ Antiox $\left.^{\bullet+}\right)=$ Gibbs free energy of cation radical. $G\left(H^{+}\right)=$Gibbs free energy of proton.

$G\left(R^{-}\right)=$Gibbs free energy of free radical anion.

$G\left(H_{n-1}\right.$ Antiox $\left.^{-}\right)=$Gibbs free energy of anion.

In the above calculations, the values of $-3.72 \mathrm{~kJ} / \mathrm{mol}$ and $-26.28 \mathrm{~kJ} / \mathrm{mol}$ were employed as the Gibbs free energy of the electron $\left(\mathrm{e}^{-}\right)$and proton $\left(\mathrm{H}^{+}\right)$respectively $[17,42]$.

\section{Results}

\section{Discussions}

\subsection{Virtual screening results}

The predicted activities and leverage values of the designed hydrazone antioxidants are presented in Table 1. The applicability domain of the hydrazone model has a leverage threshold, $h^{*}$ value of 0.375 . All the developed molecules were found within the applicability domain of the model except MHD 06, MHD 15, MHD 24, and MHD 25. Also, majority of the molecules have improved antioxidant activities compared to MHD 10 with MHD 17, MHD 21 and MHD 22 having the best $p I C_{50}$ values of $6.851,6.610$ and 6.783, respectively. These molecules were subsequently selected and subjected to quantum 
chemical calculations in order to investigate their preferred mechanism of free radical scavenge. The molecular structure and carbon atom numbering for these three compounds are presented in Fig. 2.

\subsection{Analysis of the HAT mechanism}

The computed BDE results for MHD 017, MHD 021 and MHD 022 are presented in Table 2. For MHD 017, the $8-\mathrm{NH}$ position has the highest $\mathrm{BDE}$ value of 379.156 $\mathrm{kJ} / \mathrm{mol}$. This is closely followed by the $14-\mathrm{OH}$ position with a value of $373.984 \mathrm{~kJ} / \mathrm{mol}$. These high values of BDE could be attributed to the tendency of the hydrogen atoms at these positions to form intramolecular hydrogen bonds with the adjacent carbonyl group of the parent molecule. For this reason, hydrogen atom abstraction is more difficult at these positions in comparison to the other positions. Also, HAT occurs more easily at the $10-\mathrm{OH}$ position since it has the lowest BDE value of $255.968 \mathrm{~kJ} / \mathrm{mol}$. A similar trend is observed for MHD 021 where the 14- $\mathrm{NH}$ position has the highest $\mathrm{BDE}$ value of $387.742 \mathrm{~kJ} / \mathrm{mol}$ due to the possible formation of an intramolecular hydrogen bond with the adjacent ketone group of the parent molecule. While the 10$\mathrm{OH}$ position has the lowest BDE value of $296.506 \mathrm{~kJ} /$ mol. Therefore HAT occurs more readily at this position. An examination of the BDE results of MHD 022 reveals that apart from the $10-\mathrm{OH}$ and $14-\mathrm{SH}$ positions which have lower BDE values of $305.800 \mathrm{~kJ} / \mathrm{mol}$ and $307.060 \mathrm{~kJ} / \mathrm{mol}$, the $2-\mathrm{OH}, 4-\mathrm{NH}, 8-\mathrm{NH}$ and $12-\mathrm{OH}$ positions have very close and higher $\mathrm{BDE}$ results of $348.097 \mathrm{~kJ} / \mathrm{mol}, \quad 356.551 \mathrm{~kJ} / \mathrm{mol}, \quad 365.609 \mathrm{~kJ} / \mathrm{mol}$ and $341.244 \mathrm{~kJ} / \mathrm{mol}$, respectively. Based on this result, the preferred site of free radical scavenge for MHD 022 is the $10-\mathrm{OH}$ and $14-\mathrm{SH}$ positions. The lower $\mathrm{BDE}$ value of MHD 022 14-SH against the higher values observed for MHD 017 14-OH and MHD 021 14-NH could be attributed to the less electronegative nature of sulphur in comparison to oxygen or nitrogen which form stronger intramolecular hydrogen bonds with the adjacent carbonyl group of the parent molecule. From the ongoing discussions, we observe that for MHD 017, MHD 021 and MHD 022 the lowest values of BDE occurred at the
10-OH positions on the A ring for each of the molecules with values of $255.968 \mathrm{~kJ} / \mathrm{mol}, 296.506 \mathrm{~kJ} / \mathrm{mol}$ and $305.800 \mathrm{~kJ} / \mathrm{mol}$. These results are by far lower than the $\mathrm{BDE}$ of phenol $(327.550 \mathrm{~kJ} / \mathrm{mol})$ at the same level of theory, which is generally chosen as the reference compound. This implies that the $-\mathrm{OH}$ group at this position is the possible set of free radical scavenge and contributes mainly to the antioxidant activities of hydrazone derivatives through the $\mathrm{HAT}$ mechanism. While the $-\mathrm{OH}$ and $-\mathrm{NH}$ groups at other positions in these molecules have relatively little influence on the HAT mechanism.

\subsection{Analysis of the spin density distribution}

Apart from the magnitude of the BDE, another important factor that influences the antioxidant activity of phenolic antioxidants is the stability of the radical. The radical spin density distribution is very useful in rationalizing the stability of a given radical species $[44,45,47]$. The spin density results on the radicals of MHD 017, MHD 021 and MHD 022 are also presented in Table 2. For a given radical, the lower the spin density, the higher the delocalisation of the spin density in the radical, the easier the radical is formed, the lower the BDE. For instance, among the MHD 017, MHD 021 and MHD 022 molecule, the $10-\mathrm{OH}$ radicals for each of the considered compounds have the lowest spin density values of $0.000121,0.000181$ and 0.000219 , respectively. These positions also possess the lowest BDE values (Table 2). Based on these results, the radicals produced at the 10-OH position for each of these antioxidants are the most stable. This position also represents the most favoured site for free radical attack based on the HAT mechanism.

\subsection{Analysis of SET-PT mechanism}

The adiabatic ionization potential (AIP) and proton dissociation enthalpy (PDE) values for MHD 017, MHD 021 and MHD 022 molecules and their radicals were calculated and presented in Table 2. The first step of SET-PT mechanism is characterized by AIP. Apart from MHD $02212-\mathrm{OH}$ with an AIP value of $595.379 \mathrm{~kJ} / \mathrm{mol}$, the other scavenging sites of the considered molecules

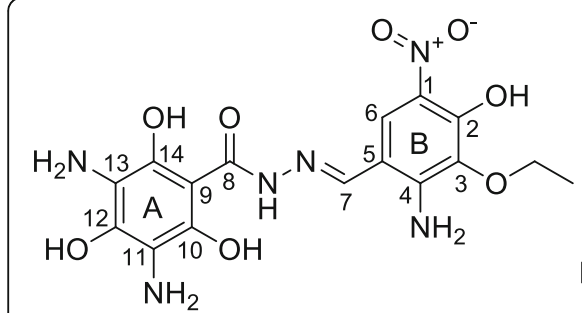

MHD 017<smiles>CCOc1c(N)c(/C=N/NC(=O)c2[14cH][14c](N)[14cH][14cH]c2N)cc([N+](=O)[O-])c1O</smiles>

MHD 021<smiles>CCOc1c(N)c(/C=N/NC(=O)c2c(O)cc(O)cc2S)cc([N+](=O)[O-])c1O</smiles>

MHD 022

Fig. 2 Molecular structure and carbon atom numbering of MHD 017, MHD 021 and MHD 022 
Table 2 Antioxidant properties of designed hydrazone derivatives calculated at the B3LYP/6-311G* level in a vacuum

\begin{tabular}{|c|c|c|c|c|c|c|}
\hline \multirow[t]{2}{*}{ Comp no. } & \multirow{2}{*}{$\begin{array}{l}\text { HAT } \\
\text { BDE (KJ/mol) }\end{array}$} & \multicolumn{2}{|l|}{ SET-PT } & \multicolumn{2}{|l|}{ SPLET } & \multirow{2}{*}{$\begin{array}{l}\text { Spin } \\
\text { density }\end{array}$} \\
\hline & & AIP (KJ/mol) & PDE (KJ/mol) & $\mathrm{PA}(\mathrm{KJ} / \mathrm{mol})$ & ETE $(\mathrm{KJ} / \mathrm{mol})$ & \\
\hline MHD 017 2-OH & 347.755 & 432.835 & 1236.742 & 1388.443 & 281.133 & 0.000225 \\
\hline MHD 017 4-NH & 357.260 & 438.453 & 1240.628 & 1396.924 & 282.157 & 0.000573 \\
\hline MHD 017 8-NH & 379.156 & 449.900 & 1251.077 & 1406.743 & 294.235 & 0.000255 \\
\hline MHD 017 10-OH & 255.968 & 385.996 & 1191.793 & 1352.553 & 225.236 & 0.000121 \\
\hline MHD 017 11-NH & 318.376 & 424.591 & 1215.607 & 1352.500 & 287.697 & 0.000583 \\
\hline MHD 017 12-OH & 278.180 & 397.837 & 1202.164 & 1375.683 & 224.317 & 0.000123 \\
\hline MHD 017 13-NH & 321.422 & 397.863 & 1245.38 & 1535.419 & 107.824 & 0.000604 \\
\hline MHD 017 14-OH & 373.984 & 379.878 & 1315.927 & 1398.026 & 297.779 & 0.000217 \\
\hline MHD $0212-\mathrm{OH}$ & 343.686 & 417.659 & 1247.848 & 1403.487 & 262.020 & 0.000217 \\
\hline MHD 021 4-NH & 354.293 & 423.278 & 1252.836 & 1410.734 & 265.380 & 0.000553 \\
\hline MHD 021 8-NH & 368.576 & 378.356 & 1312.041 & 1413.333 & 277.064 & 0.000396 \\
\hline MHD 021 10-OH & 296.506 & 354.464 & 1263.863 & 1347.354 & 270.973 & 0.000181 \\
\hline MHD 021 12-NH & 370.886 & 442.418 & 1250.289 & 1464.583 & 228.124 & 0.000717 \\
\hline MHD 021 14-NH & 387.742 & 342.517 & 1367.045 & 1519.167 & 190.396 & 0.000746 \\
\hline MHD 022 2-OH & 348.097 & 436.510 & 1233.407 & 1383.323 & 286.594 & 0.000222 \\
\hline MHD 022 4-NH & 356.551 & 443.468 & 1234.904 & 1414.436 & 263.936 & 0.000571 \\
\hline MHD 022 8-NH & 365.609 & 421.571 & 1265.859 & 1368.043 & 319.387 & 0.000382 \\
\hline MHD 022 10-OH & 305.800 & 386.022 & 1241.599 & 1305.635 & 321.986 & 0.000219 \\
\hline MHD 022 12-OH & 341.244 & 595.379 & 1067.686 & 1355.966 & 307.100 & 0.000316 \\
\hline MHD 022 14-SH & 307.060 & 384.184 & 1244.697 & 1276.256 & 352.626 & 0.001080 \\
\hline Phenol & 327.550 & 572.776 & 1076.594 & 1462.892 & 186.479 & \\
\hline
\end{tabular}

have AIP values well below that of phenol $(572.776 \mathrm{~kJ} /$ $\mathrm{mol}$ at the same level of theory), which is chosen as our reference molecule (Table 2). This is an indication that the electron-donating ability of these molecules at the various considered sites is stronger than that of phenol. Also, the trend of the AIP results is significantly different from those of BDE for the considered molecules. This discrepancy could be attributed to the fact that $\mathrm{BDE}$ is influenced by local phenomena resulting from the various substituents in the molecule, whereas AIP results are influenced by the structure of the entire molecule (extended delocalization and conjugation of the $\pi-$ electrons) [44, 45]. For MHD 017, MHD 021 and MHD 022 the lowest value of AIP is found for MHD 017 14$\mathrm{OH}(379.878 \mathrm{~kJ} / \mathrm{mol}), \mathrm{MHD} 021$ 14- $\mathrm{NH}(342.517 \mathrm{~kJ} / \mathrm{mol})$ and MHD $02214-\mathrm{SH}(384.184 \mathrm{~kJ} / \mathrm{mol})$, respectively. For each of these molecules, these sites possess stronger electron-donating ability in comparison to the other sites.

The PDE characterizes the second step of the SET-PT mechanism. For each of the molecules MHD 017, MHD 021 and MHD 022, the highest values of PDE occurred at the $8-\mathrm{NH}, 14-\mathrm{NH}$ and $8-\mathrm{NH}$ positions, respectively. This trend is analogous to those of BDE where these sites also record the highest values. This could be attributed to the fact that the second step of the SET-PT mechanism results in the generation of free radicals as in the HAT mechanism.

From the thermodynamic point, the first step is the most important for reactions that involve multiple-step mechanisms. Consequently, the results of AIP determine the order and magnitude in which these molecules undergo the SET-PT mechanism.

\subsection{Analysis of SPLET mechanism}

The proton affinity (PA) and electron transfer enthalpy (ETE) values for MHD 017, MHD 021 and MHD 022 hydrazone antioxidant molecules are presented in Table 2. The PA value is the antioxidant parameter that characterizes the first step of SPLET mechanism. The second step is characterized by ETE. For MHD 017, MHD 021 and MHD 022, the lowest observed PA values are $1352.500 \mathrm{~kJ} / \mathrm{mol}, 1347.354 \mathrm{~kJ} /$ $\mathrm{mol}$ and $1276.256 \mathrm{~kJ} / \mathrm{mol}$ which occur at the $11-\mathrm{NH}$, $10-\mathrm{OH}$ and 14-SH positions, respectively. For each of these molecules, these are the most favoured sites for deprotonation to generate highly stabilized anions. PA results at these sites are also more favourable when compared with that of phenol which has a value of $1462.892 \mathrm{~kJ} / \mathrm{mol}$. 
The ETE results for MHD 017, MHD 021 and MHD 022 recorded lowest values at the $13-\mathrm{NH}, 14-\mathrm{NH}$ and $4 \mathrm{NH}$ respectively. These are the sites that are most favoured to undergo electron transfer in the second step of the SPLET mechanism in each of the considered molecules. When the ETE results are compared with those of AIP, the ETE values are found to be lower. Accordingly, the single-electron transfer from the neutral form of the hydrazone antioxidant to the free radical is less favourable to that from the anionic form.

\subsection{Thermodynamically preferred mechanism}

The results of the Gibbs free energy change of reactions of inactivation of $\mathrm{HOO}$. and $\mathrm{CH}_{3} \mathrm{OO}$. via HAT, SET-PT and SPLET mechanisms by MHD 017, MHD 021 and MHD 022 molecules are presented in Tables 3 and 4, respectively. The values of the reaction Gibbs free energy $\left(\Delta_{r} G\right)$ are quite helpful in the assignment of the free radical-scavenging potency of molecules, because more negative values indicate the thermodynamically more preferred reactions. The results presented in Table 3 reveal that MHD 017 (at the 10- OH, 11- NH and 12-OH), MHD 021 (at the 10-OH) and MHD 022 (at the 10-OH and 14-SH) sites could scavenge HOO. by HAT and

Table 3 The reaction Gibbs free energy $\left(\Delta_{r} G\right.$ in $\left.\mathrm{kJ} / \mathrm{mol}\right)$ of scavenging $\mathrm{HOO}$. radical by hydrazone antioxidants at the B3LYP/6-311G* level in a vacuum

\begin{tabular}{|c|c|c|c|c|c|}
\hline \multirow[t]{2}{*}{ Comp no. } & \multirow{2}{*}{$\begin{array}{l}\text { HAT } \\
\Delta_{r} G_{\mathrm{BDE}}\end{array}$} & \multicolumn{2}{|l|}{ SET-PT } & \multicolumn{2}{|l|}{ SPLET } \\
\hline & & $\Delta_{r} G_{\text {AIP }}$ & $\Delta_{r} G_{P D E}$ & $\Delta_{r} G_{P A}$ & $\Delta, G_{E T E}$ \\
\hline HD 017 2-OH & 24.580 & 562.647 & -538.067 & -248.081 & 272.661 \\
\hline HD 017 4-NH & 36.158 & 568.870 & -532.711 & -238.130 & ס2ר ריר \\
\hline HD 017 8-NH & 56.217 & 580.159 & & & 283.872 \\
\hline 1HD 017 10-OH & -66.310 & 515.782 & -582.097 & -283.683 & \\
\hline HD 017 11-NH & -2.200 & 554.351 & -556.551 & -28 & 281.535 \\
\hline HD 017 12-OH & -43.340 & 527.702 & -571.044 & -260.473 & 217132 \\
\hline 1HD 017 13-NH & 1.4492 & 527.754 & -526.305 & -101.447 & 102.896 \\
\hline HD 017 14-OH & 49.286 & & -461.298 & -237.894 & \\
\hline HD $0212-\mathrm{OH}$ & 20.353 & 547.104 & -526.751 & -232.538 & 252.891 \\
\hline 1HD 021 4-NH & 33.034 & 553.484 & -520.450 & -223.506 & 256.540 \\
\hline IHD 021 8-NH & 45.636 & 509.612 & -463.976 & -219.699 & 265.336 \\
\hline MHD 021 10-OH & -24.410 & 486.298 & -510.710 & -285.652 & 261. \\
\hline 1HD 021 12-NH & 51.255 & 573.701 & -522.446 & -168.686 & 219.941 \\
\hline MHD 021 14-NH & 67.166 & 474.378 & -407.2 & -115.204 & 182.370 \\
\hline MHD $0222-\mathrm{OH}$ & 25.105 & 566.586 & -541.481 & -252.728 & 277.833 \\
\hline MHD 022 4-NH & 36.027 & 574.173 & -538 & -243.591 & 279.618 \\
\hline MHD 022 8-NH & 42.696 & 552.749 & -510.053 & -265.436 & 308.131 \\
\hline MHD 022 10-OH & -14.650 & 516.806 & -531.451 & -327.765 & 313.120 \\
\hline MHD 022 12-OH & 19.775 & 724.352 & -704.577 & -278.458 & 298.233 \\
\hline VHD 022 14-SH & -13.910 & 515.677 & -529.587 & -356.068 & 342.158 \\
\hline
\end{tabular}

Table 4 The reaction Gibbs free energy $\left(\Delta_{,} G \mathrm{in} \mathrm{kJ} / \mathrm{mol}\right)$ of scavenging $\mathrm{CH}_{3} \mathrm{OO}$. radical by hydrazone antioxidants at the B3LYP/6-311G* level in a vacuum

\begin{tabular}{|c|c|c|c|c|c|}
\hline \multirow[t]{2}{*}{ Comp No } & \multirow{2}{*}{$\begin{array}{l}\text { HAT } \\
\triangle_{r} G_{B D E}\end{array}$} & \multicolumn{2}{|l|}{ SET-PT } & \multicolumn{2}{|l|}{ SPLET } \\
\hline & & $\Delta_{r} G_{A I P}$ & $\triangle_{r} G_{P D E}$ & $\triangle_{r} G_{P A}$ & $\Delta_{r} G_{E T E}$ \\
\hline HD 017 2-OH & 27.817 & 524.625 & -496.808 & -206.821 & 234.638 \\
\hline MHD 017 4-NH & 39.396 & 530.847 & -491.452 & -196.871 & 236.266 \\
\hline HD 017 8-NH & 59.454 & 542.137 & -482.682 & -186.395 & 245.849 \\
\hline IHD 017 10-OH & -63.078 & 477.760 & -540.837 & -242.423 & 179.345 \\
\hline MHD 017 11-NH & 1.0371 & 516.328 & -515.291 & -242.475 & 243.513 \\
\hline HD 017 12-OH & -40.105 & 489.679 & -529.784 & -219.214 & 179.109 \\
\hline HD 017 13-NH & 4.6865 & 489.732 & -485.045 & -60.187 & \\
\hline IHD 017 14-OH & 52.523 & 472.561 & -420.038 & -196 & \\
\hline HD $0212-O H$ & 23.590 & 509.082 & -485.492 & -191.278 & 214.868 \\
\hline HD 021 4-NH & 36.271 & 515.462 & -479.191 & -182.246 & 218.518 \\
\hline IHD 021 8-NH & 48.874 & 471.590 & -422.716 & -178.439 & 227.313 \\
\hline HD 021 10-OH & -21.175 & 448.275 & -469.450 & -244.392 & 223.217 \\
\hline VHD 021 12-NH & 54.492 & 535.678 & -481.186 & -127.426 & 181.918 \\
\hline HDD 021 14-NH & 70.403 & 436.356 & -365.953 & -73.9446 & 144.347 \\
\hline MHD 022 2-OH & 28.342 & 528.563 & -500.221 & -211.468 & 239.811 \\
\hline MHD 022 4-NH & 39.264 & 536.151 & -496.886 & -202.332 & 241.596 \\
\hline MHD 022 8-NH & 45.933 & 514.727 & -468.793 & -224.176 & 270.109 \\
\hline MHD 022 10-OH & -11.408 & 478.784 & -490.191 & -286.505 & 275.097 \\
\hline MHD 022 12-OH & 23.012 & 686.329 & -663.317 & -237.198 & 260.211 \\
\hline MHD 022 14-SH & -10.673 & 477.655 & -488.327 & -314.808 & 304.135 \\
\hline
\end{tabular}

SPLET mechanisms because these processes are exergonic. The results at the other positions are thermodynamically unfavourable due to their endergonic nature. In the SPLET pathway, we observe that the exergonicity of $\Delta_{r} G_{\mathrm{PA}}$ results overwhelm the endergonicity of the $\Delta_{r} G_{\mathrm{ETE}}$ results. Since a thermodynamically unfavourable reaction could be driven by a thermodynamically favourable reaction that is coupled to it, the entire SPLET mechanism is exergonic. A similar result to the $\mathrm{HOO}$. scavenge is observed for the $\mathrm{CH}_{3} \mathrm{OO}$. scavenge except for the 11-NH position of MHD 017 molecule where the reaction is endergonic (Table 4). On the basis of the exergonicity of the calculated reaction Gibbs free energy for each considered hydrazone antioxidant molecule, the 10-OH position appears to be the most efficient site for the scavenge of $\mathrm{HOO}$. and $\mathrm{CH}_{3} \mathrm{OO}$. in the studied environment via HAT and SPLET mechanisms. The Gibbs free energy of these reactions also indicates that these molecules are more efficient in scavenging $\mathrm{HOO}$. than $\mathrm{CH}_{3} \mathrm{OO}$. On the basis of the calculated reaction free energies, MHD 017 at the $10-\mathrm{OH}$ site possessed the highest free radical-scavenging potency for $\mathrm{HOO}$ than $\mathrm{CH}_{3} \mathrm{OO}$. via HAT and SPLET mechanisms. Subsequently, the radical-scavenging mechanism of this 
molecule by HAT and SPLET mechanisms are presented in Scheme 1(a) and (b) respectively.

\subsection{Analysis of frontier molecular orbitals}

The results of frontier orbital distribution and energy for MHDM 017, MHDM 021 and MHDM 022 calculated at the B3LYP/6-311G* level in the gas phase are presented in Fig. 3. From Fig. 3, we observe that the LUMO is localized on ring $B$ and its associated oxygen and nitrogen atoms in its functional groups for the three molecules. While the HOMO is delocalised almost over the entire molecules, they are observed to be highly concentrated on the nitrogen atoms of the hydrazine group. For MHDM 022, this includes the sulphur atom to which the hydrogen atom is attached. For MHDM 021, this includes the conjugated carbon atoms of ring $\mathrm{A}$, and the nitrogen atom of the amino group. In all the molecules, they are equally distributed on the oxygen atoms of the hydroxyl groups. These sites with a high concentration of the HOMO possess higher tendency to lose electrons [31, $40,44,45]$. These are the sites for free radical scavenge for the associated molecules.

MHDM 021 has the highest HOMO value of -5.50 $\mathrm{eV}$, followed by MHDM 017 with a value of -5.94 $\mathrm{eV}$. This is closely followed by MHDM 022 with a value of $-6.00 \mathrm{eV}$. Based on this result, MHD 021 has the greatest capacity to lose electrons, because the higher the HOMO energy, the easier the electron is excited. While MHDM 022 has the weakest electron-donating ability among the considered molecules, the sequence of predicted electron-donating ability of these molecules as predicted by the HOMO energies is in very good agreement with that of the predicted AIP results (Table 2).

\section{Conclusion}

In this research, virtual screening by the method of quantitative structure-activity relationship was employed in the design of new hydrazone antioxidants with the earlier proposed antioxidant model for hydrazones. The structure and antioxidant activity of these compounds were successfully predicted in this work with (E)-3,5-diamino- $\mathrm{N}^{\prime}$-(2-amino3-ethoxy-4-hydroxy-5-nitrobenzylidene)-2,4,6-trihydroxybenzohydrazone (MHD 017) having the best antioxidant activity $\left(p \mathrm{IC}_{50}=6.851\right)$. This demonstrates the ability of the developed hydrazone antioxidant model to reduce the time and cost of synthesizing new hydrazone antioxidants in addition to the investigation of their antioxidant activities.

The thermodynamics of three of the best antioxidants (MHD 017, MHD 021 and MHD 022) were investigated by the DFT method in the gas phase. In order to evaluate the possible mechanism of free radical scavenge by these molecules, thermodynamic parameters such as BDE, PDE, AIP, PA and ETE were calculated. The radical spin density was also calculated in order to rationalize the observed differences in the BDE results. The sequence of hydrogen donation by these molecules is MHD $017>$ MHD $022>$ MHD 021 and is in line with their predicted antioxidant activities. The trend of the BDE results is significantly different from those of the AIP, but analogous to those of PDE. Also, from the generated results for AIP and ETE, the single-electron transfer from the neutral form of the hydrazone antioxidant to the free radical is less favourable to that from the anionic form.

The thermodynamically preferred mechanism of reaction was investigated by calculating the reaction Gibbs free energy for inactivating $\mathrm{HOO}$. and $\mathrm{CH}_{3} \mathrm{OO}$. at the various reaction sites in each molecule. The observed results indicate that HAT and SPLET mechanisms are thermodynamically

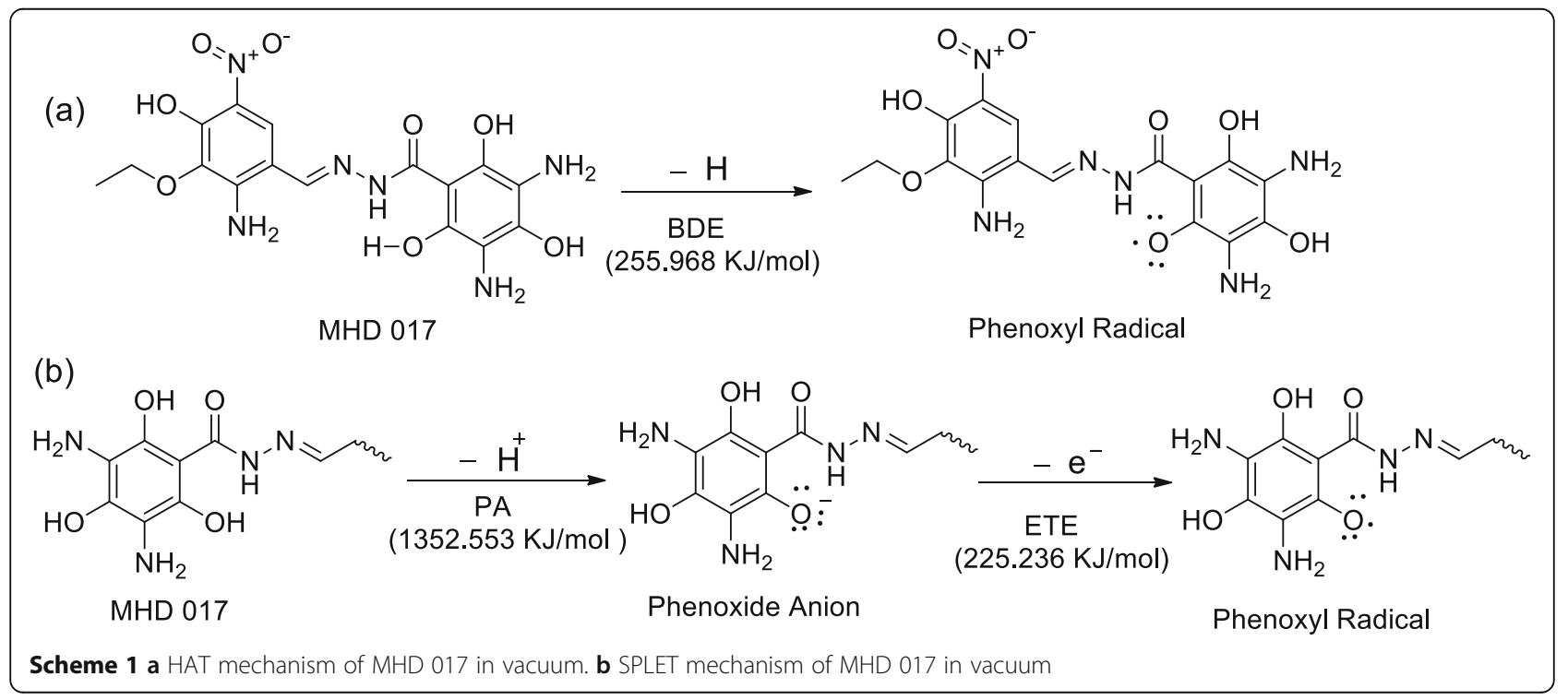



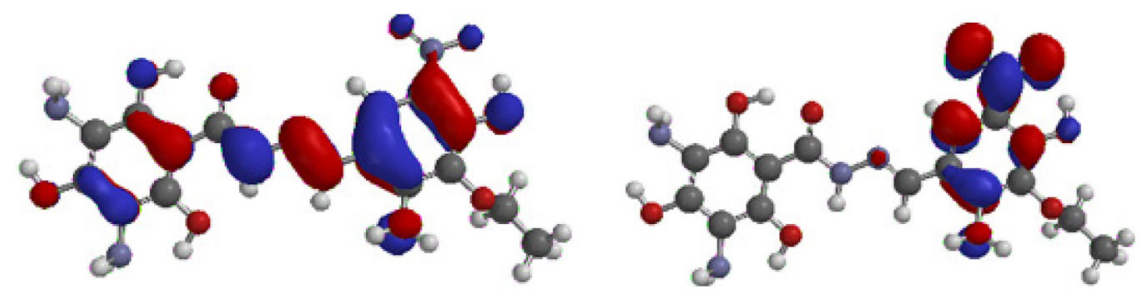

$-5.94$

MHD 017

$-2.43$

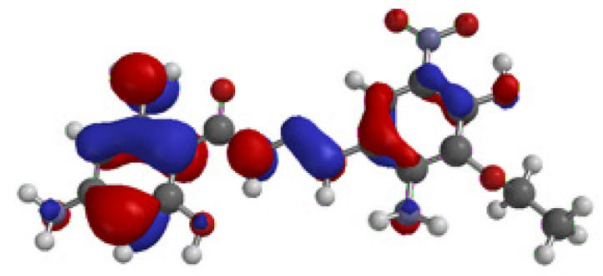

$-5.50$

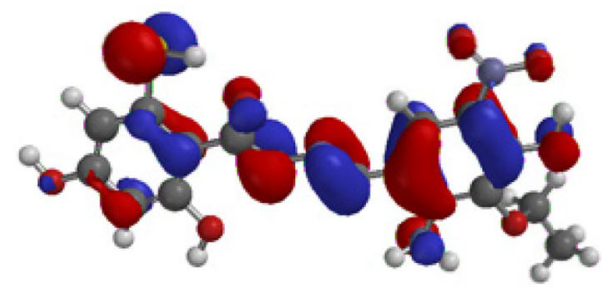

$-6.00$
MHD 022

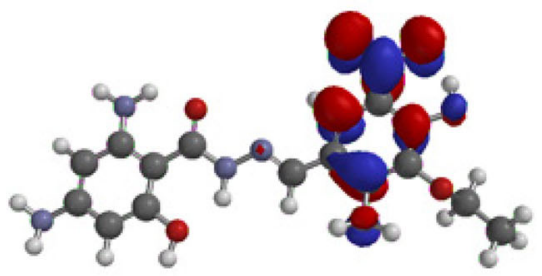

$-2.29$

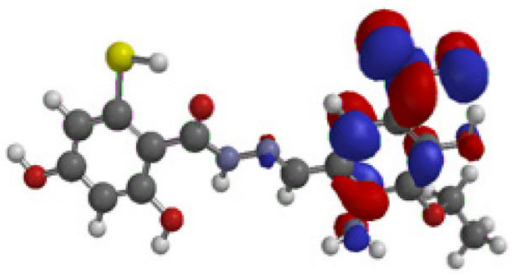

$-2.47$

LUMO

Fig. 3 The orbital distribution and energy (in eV) of HOMO and LUMO for MHD 017, MHD 021 and MHD 022 computed at the B3LYP/6-311G* level in the gas phase

feasible at various sites in each molecule with best results observed at the $10-\mathrm{OH}$ site based on the negative values of their reaction Gibbs free energy. On the other hand, the SET-PT mechanism was thermodynamically unfeasible for all the molecules as their reaction processes were endergonic. Among the tested molecules, MHD 017 which was earlier proposed to have the best antioxidant activity exhibited the highest free radical-scavenging potential against $\mathrm{HOO}$. than $\mathrm{CH}_{3} \mathrm{OO}$ at the $10-\mathrm{OH}$ site upon thermodynamic studies. The present research not only did succeed in the elucidation of the free radical-scavenging mechanism of the considered hydrazone derivatives, but also will stimulate subsequent exploitation of these compounds in the field of food chemistry and pharmacy.

\section{Abbreviations}

AIP: Adiabatic ionization potential; B3LYP: Becke's three-parameter Lee-YangParr hybrid functional; BDE: Bond dissociation enthalpy; DFT: Density functional theory; ETE: Electron transfer enthalpy; HAT: Hydrogen atom transfer; HOMO: Highest occupied molecular orbital; LUMO: Lowest unoccupied molecular orbital; PA: Proton affinity; PDE: Proton dissociation enthalpy; QSAR: Quantitative structure-activity relationship; ROS: Reactive oxygen species; SET-PT: Single-electron transfer followed by proton transfer; SPLET: Sequential proton loss electron transfer
Acknowledgements

The authors are grateful to the Physical Chemistry team in Ahmadu Bello University Zaria and Federal University Dutsinma for their assistance.

\section{Authors' contributions}

This research was designed by IOA, AU, and SEA. IOA optimized all the molecular structures. All authors participated in the calculation of the thermodynamic parameters. IOA wrote the manuscript under the supervision of $\mathrm{AU}$ and SEA. All authors read and approved the final manuscript.

\section{Funding}

Not applicable

\section{Availability of data and materials}

All data generated or analysed during this study are included in this published article.

Ethics approval and consent to participate

Not applicable

\section{Consent for publication}

Not applicable

\section{Competing interests}

The authors declare that they have no competing interests.

\section{Author details}

'Department of Applied Chemistry, Federal University Dutsinma, PMB 5001, Dutsinma, Katsina State, Nigeria. ${ }^{2}$ Department of Chemistry, Ahmadu Bello University, Zaria, Kaduna State, Nigeria. 
Received: 6 July 2019 Accepted: 6 September 2019 Published online: 28 October 2019

\section{References}

1. Alisi IO, Uzairu A, Abechi SE, Idris SO (2018) Free radical scavenging activity evaluation of hydrazones by quantitative structure activity relationship. J Mex Chem Soc 62(1):1-13. https://doi.org/10.29356/jmcs.v62i1.585

2. Amic A, Lučić B, Stepanić V, Marković Z, Marković S, Dimitrić Marković J, Amić D (2017) Free radical scavenging potency of quercetin catecholic colonic metabolites: thermodynamics of $2 \mathrm{H}+/ 2 \mathrm{e}-$ processes. Food Chem 218:144-151. https://doi.org/10.1016/j.foochem.2016.09.018

3. Anastassova NO, Yancheva DY, Mavrova AT, Kondeva-Burdina MS, Tzankova VI, Hristova-Avakumova NG, Hadjimitova VA (2018) Design, synthesis, antioxidant properties and mechanism of action of new N, $\mathrm{N}^{\prime}$-disubstituted benzimidazole-2-thione hydrazone derivatives. J Mol Struct 1165:162-176. https://doi.org/10.1016/j.molstruc.2018.03.119

4. Aradhyula BPR, Joshi N, Poluri KM, Kollipara MR (2018) Synthesis and antibacterial studies of rhodium and iridium complexes comprising of dipyridyl hydrazones. J Mol Struct 1164:191-199. https://doi.org/10.1016/j. molstruc.2018.03.058

5. Arthur DE, Uzairu A, Mamza P, Abechi SE, Shallangwa G (2018) In silico modelling of quantitative structure-activity relationship of multi-target anticancer compounds on k-562 cell line. Netw Model Anal Health Inform Bioinform 7(1). https://doi.org/10.1007/s13721-018-0168-y

6. Asadollahi T, Dadfarnia S, Shabani AMH, Ghasemi JB, Sarkhosh M (2011) QSAR models for CXCR2 receptor antagonists based on the genetic algorithm for data preprocessing prior to application of the pls linear regression method and design of the new compounds using in silico virtual screening. Molecules 16:1928-1955. https://doi.org/10.3390/ molecules16031928

7. Baldisserotto A, Demurtas M, Lampronti I, Moi D, Balboni G, Vertuani S et al (2018) Benzofuran hydrazones as potential scaffold in the development of multifunctional drugs: synthesis and evaluation of antioxidant, photoprotective and antiproliferative activity. Eur J Med Chem 156:118-125. https://doi.org/10.1016/j.ejmech.2018.07.001

8. Bartmess JE (1994) Thermodynamics of the electron and the proton. J Phys Chem 98:6420-6424. https://doi.org/10.1021/j100076a029

9. Bizarro MM, Cabral BJC, Santos RMB, Simoes JAM (1999) Substituent effects on the $\mathrm{O}-\mathrm{H}$ bond dissociation enthalpies in phenolic compounds: agreements and controversies. Pure Appl Chem 71(7):1249-1256

10. Chafai N, Chafaa S, Benbouguerra K, Hellal A, Mehri M (2019) Synthesis, spectral analysis, anti-corrosive activity and theoretical study of an aromatic hydrazone derivative. J Mol Struct 1181:83-92. https://doi.org/10.1016/j. molstruc.2018.12.073

11. Dehestani L, Ahangar N, Hashemi SM, Irannejad H, Honarchian Masihi P, Shakiba A, Emami S (2018) Design, synthesis, in vivo and in silico evaluation of phenacyl triazole hydrazones as new anticonvulsant agents. Bioorg Chem 78:119-129. https://doi.org/10.1016/j.bioorg.2018.03.001

12. Demurtas M, Baldisserotto A, Lampronti I, Moi D, Balboni G, Pacifico S et al (2019) Indole derivatives as multifunctional drugs: synthesis and evaluation of antioxidant, photoprotective and antiproliferative activity of indole hydrazones. Bioorg Chem 85:568-576. https://doi.org/10.1016/j. bioorg.2019.02.007

13. El-Din NS, Barseem A (2016) Synthesis, bioactivity and docking study of some new indole-hydrazone derivatives. J Appl Pharm Sci 6(12):075-083. https://doi.org/10.7324/JAPS.2016.601211

14. El-Sayed HA, Moustafa AH, Abd El-Moneim M, Awad HM, Esmat A (2018) Design and synthesis of hydrazide-hydrazones based 2-oxonicotinonitrile derivatives as potential antimicrobial agents. J Pharm Appl 4(2):125-131. https://doi.org/10.18576/jpac/040207

15. Emami S, Esmaili Z, Dehghan G, Bahmani M, Hashemi SM, Mirzaei H, Moradi SE (2018) Acetophenone benzoylhydrazones as antioxidant agents: synthesis, in vitro evaluation and structure-activity relationship studies. Food Chem 268:292-299. https://doi.org/10.1016/j.foodchem.2018.06.083

16. He L-Y, Qiu X-Y, Cheng J-Y, Liu S-J, Wu S-M (2018) Synthesis, characterization and crystal structures of vanadium $(V)$ complexes derived from halido-substituted tridentate hydrazone compounds with antimicrobial activity. Polyhedron. 156:105-110. https://doi.org/10.1016/j.poly.2018.09.017

17. Hwang S, Chung DS (2005) Calculation of the solvation free energy of the proton in methanol. Bull Kor Chem Soc 26:589-593
18. Kaplánek R, Havlík M, Dolenský B, Rak J, Džubák P, Konečný P et al (2015) Synthesis and biological activity evaluation of hydrazone derivatives based on a Tröger's base skeleton. Bioorg Med Chem 23(7):1651-1659. https://doi. org/10.1016/j.bmc.2015.01.029

19. Kareem HS, Ariffin A, Nordin N, Heidelberg T, Abdul-Aziz A, Kong KW, Yehye WA (2015) Correlation of antioxidant activities with theoretical studies for new hydrazone compounds bearing a 3,4,5-trimethoxy benzyl moiety. Eur J Med Chem 103:497-505. https://doi.org/10.1016/j.ejmech.2015.09.016

20. Kaya B, Özkay Y, Temel HE, Kaplancıklı ZA (2016) Synthesis and biological evaluation of novel piperazine containing hydrazone derivatives. J Chem 2016:1-7. https://doi.org/10.1155/2016/5878410

21. Lgaz H, Chung I-M, Albayati MR, Chaouiki A, Salghi R, Mohamed SK (2018) Improved corrosion resistance of mild steel in acidic solution by hydrazone derivatives: an experimental and computational study. Arab J Chem. https:// doi.org/10.1016/j.arabjc.2018.08.004

22. Li Z, Wan H, Shi Y, Ouyang P (2004) Personal experience with four kinds of chemical structure drawing software: review on ChemDraw, ChemWindow, ISIS/Draw, and ChemSketch. J Chem Inf Comput Sci 44(5):1886-1890. https://doi.org/10.1021/ci049794h

23. Maltarollo VG, de Resende MF, Kronenberger T, Lino Cl, Pinheiro Duarte Sampaio MC, da Rocha Pitta MG et al (2018) In vitro and in silico studies of antioxidant activity of 2-thiazolylhydrazone derivatives. J Mol Graphics Modell. https://doi.org/10.1016/j.jmgm.2018.10.007

24. Medina-Franco JL, Yoo J, Dueñas-González A (2015) DNA methyltransferase inhibitors for cancer therapy. Epigenet Technol Appl:265-290. https://doi. org/10.1016/b978-0-12-801080-8.00013-2

25. Melagraki G, Afantitis A, Sarimveis $H$, Koutentis PA, Kollias G, IgglessiMarkopoulou O (2009) Predictive QSAR workflow for the in silico identification and screening of novel HDAC inhibitors. Mol Divers 13(3): 301-311. https://doi.org/10.1007/s11030-009-9115-2

26. Melagraki G, Afantitis A, Sarimveis H, Koutentis PA, Markopoulos J, IgglessiMarkopoulou O (2007) Optimization of biaryl piperidine and 4-amino-2biarylurea $\mathrm{MCH} 1$ receptor antagonists using QSAR modeling, classification techniques and virtual screening. J Comput Aided Mol Des 21(5):251-267. https://doi.org/10.1007/s10822-007-9112-4

27. Mikulski D, Eder K, Molski M (2014) Quantum-chemical study on relationship between structure and antioxidant properties of hepatoprotective compounds occurring in cynara scolymus and silybum marianum. J Theor Comput Chem 13:1), 1-1),24. https://doi.org/10.1142/S0219633614500047

28. Mitra I, Saha A, Roy K (2011) Chemometric QSAR modeling and in silico design of antioxidant no donor phenols. Sci Pharm 79:31-58. https://doi. org/10.3797/scipharm.1011-02.

29. Najafi M, Mood KH, Zahedi M, Klein E (2011) DFT/B3LYP study of the substituent effect on the reaction enthalpies of the individual steps of single electron transfer-proton transfer and sequential proton loss electron transfer mechanisms of chroman derivatives antioxidant action. Comput Theor Chem 969:1-12. https://doi.org/10.1016/j.comptc.2011.05.006

30. Nenadis N, Tsimidou MZ (2012) Contribution of DFT computed molecular descriptors in the study of radical scavenging activity trend of natural hydroxybenzaldehydes and corresponding acids. Food Res Int 48:538-543. https://doi.org/10.1016/j.foodres.2012.05.014

31. Özbakır Işın D (2016) Theoretical study on the investigation of antioxidant properties of some hydroxyanthraquinones. Mol Phys 114(24):3578-3588. https://doi.org/10.1080/00268976.2016.1248514

32. Palepu NR, Richard Premkumar J, Verma AK, Bhattacharjee K, Joshi SR, Forbes $S$ et al (2018) Antibacterial, in vitro antitumor activity and structural studies of rhodium and iridium complexes featuring the two positional isomers of pyridine carbaldehyde picolinic hydrazone ligand. Arab J Chem 11(5):714-728. https://doi.org/10.1016/j.arabjc.2015.10.011

33. Qurrat-ul-Ain, Ashiq U, Jamal RA, Saleem M, Mahroof-Tahir M (2017) Alphaglucosidase and carbonic anhydrase inhibition studies of Pd (II)-hydrazide complexes. Arab J Chem 10(4):488-499. https://doi.org/10.1016/j.arabjc.2015.02.024

34. Rawat P, Singh RN, Niranjan P, Ranjan A, Holguín NRF (2017) Evaluation of antituberculosis activity and DFT study on dipyrromethane-derived hydrazone derivatives. J Mol Struct 1149:539-548. https://doi.org/10.1016/j. molstruc.2017.08.008

35. Renaud J-P, Moras D, Wurtz J-M (2007) Nuclear hormone receptors: insights for drug design from structure and modeling. Compr Med Chem II:725-747. https://doi.org/10.1016/b0-08-045044-x/00273-x

36. Rimarcik J, Lukes V, Klein E, Ilcin M (2010) Study of the solvent effect on the enthalpies of homolytic and heterolytic $\mathrm{N}-\mathrm{H}$ bond cleavage in $\mathrm{p}$ - 
phenylenediamine and tetracyano-p-phenylenediamine. J Mol Struct (THEOCHEM) 952:25-30. https://doi.org/10.1016/j.theochem.2010.04.002

37. Ruscic B (2015) Active thermochemical tables: sequential bond dissociation enthalpies of methane, ethane, and methanol and the related thermochemistry. J Phys Chem A 119(28):7810-7837. https://doi.org/10. 1021/acs.jpca.5b01346

38. Sebeka AH, Osman AM, El Sayed IE, El-Bahanasawy M, Tantawy MA (2017) Synthesis and antiproliferative activity of novel neocryptolepine-hydrazides hybrids. J App Pharm Sci 7(10):009-015. https://doi.org/10.7324/JAPS.2017.71002

39. Shao Y, Molnar LF, Jung Y, Kussmann J, Ochsenfeld C, Brown ST et al (2006) Advances in methods and algorithms in modern quantum chemistry program package. Phys Chem Chem Phys 8(27):3172-3191. https:/doi.org/ 10.1039/B517914A

40. Szeląg M, Mikulski D, Molski M (2011) Quantum-chemical investigation of the structure and the antioxidant properties of a-lipoic acid and its metabolites. J Mol Model 18(7):2907-2916. https:/doi.org/10.1007/s00894-011-1306-y

41. Tariq QU, Malik S, Khan A, Naseer MM, Khan SU, Ashraf A, Ashraf M, Rafiq M, Mahmood K, Tahir MN, Shafiq Z (2019) Xanthenone-based hydrazones as potent a-glucosidase inhibitors: synthesis, solid state self-assembly and in silico studies. Bioorg Chem 84:372-383. https://doi.org/10.1016/j.bioorg.2018.11.053

42. Tissandier MD, Cowen KA, Feng WY, Gundlach E, Cohen MH, Earhart AD, Coe JV, Tuttle TRJ (1998) The proton's absolute aqueous enthalpy and Gibbs free energy of solvation from cluster-ion solvation data. J Phys Chem A 102(40):7787-7794

43. Vyas V (2008) Virtual screening: a fast tool for drug design. Sci Pharm 76(3): 333-360. https://doi.org/10.3797/scipharm.0803-03

44. Wang G, Xue Y, An L, Zheng Y, Dou Y, Zhang L, Liu Y (2015) Theoretical study on the structural and antioxidant properties of some recently synthesised 2,4,5-trimethoxy chalcones. Food Chem 171:89-97. https://doi. org/10.1016/j.foodchem.2014.08.106

45. Xue Y, Zheng Y, An L, Dou Y, Liu Y (2014) Density functional theory study of the structure-antioxidant activity of polyphenolic deoxybenzoins. Food Chem 151:198-206. https://doi.org/10.1016/j.foodchem.2013.11.064

46. Yap CW (2011) PaDEL-descriptor: an open source software to calculate molecular descriptors and fingerprints. J Comput Chem 32(7):1466-1474. https://doi.org/10.1002/jcc.21707

47. Zheng YZ, Deng G, Liang Q, Chen DF, Guo R, Lai RC (2017) Antioxidant activity of quercetin and its glucosides from propolis: a theoretical study. Sci Rep 7:7543. https://doi.org/10.1038/s41598-017-08024-8

\section{Publisher's Note}

Springer Nature remains neutral with regard to jurisdictional claims in published maps and institutional affiliations.

\section{Submit your manuscript to a SpringerOpen ${ }^{\circ}$ journal and benefit from:}

- Convenient online submission

- Rigorous peer review

- Open access: articles freely available online

- High visibility within the field

- Retaining the copyright to your article

Submit your next manuscript at $\boldsymbol{\nabla}$ springeropen.com 